\title{
Comparative Evaluation of 12 Immature Citrus Fruit Extracts for the Inhibition of Cytochrome P450 Isoform Activities
}

\author{
Tadashi Fustia, ${ }^{a}$ Atsushi Kawase, ${ }^{a}$ Toshiro Niwa, ${ }^{a}$ Norimichi Tomohiro, ${ }^{b}$ Megumi Masuda,,${ }^{b}$ \\ Hideaki Matsuda, ${ }^{a}$ and Masahiro IWAKI*,a \\ ${ }^{a}$ School of Pharmacy, Kinki University; 3-4-1 Kowakae, Higashi-osaka, Osaka 577-8502, Japan: and ${ }^{b}$ A Pharma Kindai \\ Co., Ltd.; 1-8-17 Nipponbashi, Chuo-ku, Osaka 542-0073, Japan. \\ Received December 25, 2007; accepted February 22, 2008; published online February 26, 2008
}

In a previous study we found that $\mathbf{5 0 \%}$ ethanol extracts of immature fruits of Citrus unshiu (satsuma mandarin) have anti-allergic effects against the Type I, II and IV allergic reactions. However, many adverse interactions between citrus fruit, especially grapefruit juice, and drugs have been reported due to the inhibition of cytochrome P450 (CYP) activities. The purpose of this study was to examine the competitive inhibitory effects of extracts from immature citrus fruit on CYP activity. Extracts were prepared from 12 citrus species or cultivars, and were tested against three kinds of major CYPs, CYP2C9, CYP2D6 and CYP3A4, in human liver microsomes. We also estimated the amounts of flavonoids (narirutin, hesperidin, naringin and neohesperidin) and furanocoumarins (bergapten, 6', $7^{\prime}$-dihydroxybergamottin and bergamottin) in each extract using HPLC. Citrus paradisi (grapefruit) showed the greatest inhibition of CYP activities, while Citrus unshiu which has an antiallergic effect, showed relatively weak inhibitory effects. Extracts having relatively strong inhibitory effects for CYP3A4 tended to contain higher amounts of naringin, bergamottin and $6^{\prime}, 7^{\prime}$-dihydroxybergamottin. These results, providing comparative information on the inhibitory effects of citrus extracts on CYP isoforms, suggest that citrus extracts containing high levels of narirutin and hesperidin and lower levels of furanocoumarins such as $C$. unshiu are favorable as antiallergic functional ingredients.

Key words citrus extract; cytochrome P450; inhibition; flavonoid; furanocoumarin

Many flavonoids and furanocoumarins are present in fruits, vegetables and beverages derived from plants. Flavonoids have been described as health-promoting and disease-preventing dietary supplements. ${ }^{1)}$ Recently, dietary supplements and herbal products containing flavonoids have become very popular due to increased public interest in healthpromotion and disease-prevention. Flavonoid- or furanocoumarin-drug interactions have been reported in clinical studies. For example, flavonoids and furanocoumarins in grapefruit juice affect the oral bioavailability of a variety of drugs, including the dihydropyridine calcium channel blockers, cyclosporin A, midazolam, triazolam, terfenadine, saquinavir and ethynylestradiol. ${ }^{2-4)}$ Many instances of flavonoid- or furanocoumarin-drug interactions have also been reported from rodent studies. ${ }^{1-3)}$ These interactions could mainly take place in small intestine. On average, CYP3A and CYP2C9 represent the major pieces of the intestinal CYP, accounting for $80 \%$ and $15 \%$, respectively, of total immunoquantified CYP. CYP2D6, 2C19 and 2J2 represent a few percent of intestinal CYP.

Citrus fruit extracts contain flavonoids and furanocoumarins. Our previous investigation demonstrated that immature citrus fruit extracts contained relatively high amounts of flavonoids, such as hesperidin, narirutin and naringin.6) Hesperidin has an antiallergic effect by inhibiting histamine release from mast cells. On the other hand, it is reported that furanocoumarins such as bergamottin, $6^{\prime}, 7^{\prime}$-dihydroxybergamottin $\left(6^{\prime}, 7^{\prime}\right.$-DHB), bergaptol and bergapten are involved in CYP3A4 inhibition. ${ }^{7,8)}$ Furanocoumarins also inhibit the activities of other CYP isoforms such as CYP1A2, CYP2C9, CYP2C19, CYP2D6 and CYP2E1. ${ }^{9,10)}$ Inhibition of CYP enzymes, including CYP1A1, CYP1A2, CYP2E1 and CYP3A4 by competitive binding and/or mechanism-based inhibition also occurs. ${ }^{4,11)}$ However, there is little comprehensive infor- mation about the inhibitory effects of citrus extracts on CYP activities. We investigated the effects of extracts from immature fruits of 12 citrus species or cultivars on the activities of CYP3A4, 2D6 and 2C9 existing in small intestine because these CYP isoforms exist relatively abundantly in small intestine. We used the extracts rather than juices of the immature fruits to test the possibility for medicinal resources. The quantitative correlation of the flavonoids or furanocoumarins contents of the citrus extracts with their inhibitory effect on CYP3A4 activity was also examined. This study also indicated that the inhibitory effects of immature Citrus unshiu (satsuma mandarin) on CYP activities are relatively low among the 12 citrus extracts examined.

\section{MATERIALS AND METHODS}

Materials Extracts from immature fruit of 12 Citrus species or cultivars were used; C. iyo, C. limon, C. naruto, $C$. sinensis var. brasiliensis, C. aurantiun var. daidai, C. sulcata, C. reticulata, C. grandis, C. paradisi, C. sinensis, C. natsudaidai and C. unshiu, which were harvested in August and provided by the Yuasa Experimental Farm of Kinki University. Mixed gender pooled 50 human liver microsomes were obtained from XenoTech (Lenexa, KS, U.S.A.). Midazolam injection $\left(10 \mathrm{mg} / 2 \mathrm{ml}\right.$, Dormicum $\left.{ }^{\circledR}\right)$ was purchased from Astellas Pharma (Tokyo, Japan). 1'-Hydroxymidazolam, dextromethorphan and $O$-demethyldextromethorphan were obtained from Daiichi Pure Chemicals Co., Ltd. (Tokyo, Japan). $\quad \beta$-NADP ${ }^{+}$, glucose-6-phosphate, and glucose-6phosphate dehydrogenase were purchased from Oriental Yeast Co. (Tokyo, Japan). All other chemicals were reagent grade products obtained commercially.

Preparation of Extracts of the Fruits The extracts were prepared from the fruits according to a standard method. ${ }^{6}$ In 
Table 1. The Yield for Each Citrus Fruit and the Values of $\mathrm{IC}_{50}$ for Each CYP Isoform of Citrus Extracts in Decreasing Order of CYP3A4 IC 50

\begin{tabular}{|c|c|c|c|c|}
\hline & \multirow{2}{*}{ Yield (\%) } & \multicolumn{3}{|c|}{$\mathrm{IC}_{50}(\mathrm{mg} / \mathrm{ml})$} \\
\hline & & $\begin{array}{c}\text { CYP3A4 } \\
\left.\text { Estimation S.E. }{ }^{a}\right)\end{array}$ & $\begin{array}{c}\text { CYP2D6 } \\
\text { Estimation S.E. }^{a)}\end{array}$ & $\begin{array}{c}\text { CYP2C9 } \\
\text { Estimation S.E. }{ }^{a)}\end{array}$ \\
\hline C. unshiu & 24.7 & $0.88(0.22)$ & $3.23(0.82)$ & $1.02(0.12)$ \\
\hline C. sulcata & 19.7 & $0.54(0.19)$ & $1.88(0.28)$ & $0.69(0.09)$ \\
\hline C. iyo & 17.4 & $0.45(0.09)$ & $0.38(0.07)$ & $0.78(0.08)$ \\
\hline C. sinensis var. grasiliensis & 17.8 & $0.30(0.14)$ & $1.32(0.18)$ & $0.57(0.22)$ \\
\hline C. sinensis & 14.1 & $0.27(0.09)$ & $0.49(0.19)$ & $0.29(0.09)$ \\
\hline C. reticulata & 20.0 & $0.22(0.09)$ & $1.54(0.46)$ & $0.13(0.09)$ \\
\hline C. grandis & 14.4 & $0.12(0.01)$ & $0.62(0.12)$ & $0.03(0.01)$ \\
\hline C. naruto & 14.0 & $0.12(0.01)$ & $1.27(0.17)$ & $0.04(0.01)$ \\
\hline C. natsudaidai & 23.7 & $0.11(0.03)$ & $1.50(0.30)$ & $0.05(0.01)$ \\
\hline C. aurantiun var. daidai & 19.6 & $0.11(0.01)$ & $1.12(0.32)$ & $0.03(0.01)$ \\
\hline C. limon & 20.0 & $0.07(0.01)$ & $1.93(0.33)$ & $0.11(0.01)$ \\
\hline C. paradisi & 14.4 & $0.06(0.01)$ & $0.40(0.10)$ & $0.06(0.01)$ \\
\hline
\end{tabular}

a) Standard error of estimation value calculated from the nonlinear curve fitting program WinNonlin.

brief, the crushed drying fruits $(300 \mathrm{~g})$ were extracted once with $50 \%$ ethanol (31) under reflux for $2 \mathrm{~h}$. The filtrates were concentrated under reduced pressure and lyophilized. In Table 1, the yield (\%) of extract for each fruit was shown.

Citrus Extracts' Inhibition of CYP Isoforms Midazolam 1'-hydroxylation (MD1H) activity for CYP3A4 and dextromethorphan $O$-demethylation (DMOD) activity for CYP2D6 in the presence or absence of the citrus extracts were determined as follows. An incubation mixture $(0.2 \mathrm{ml}$ total volume) was prepared, containing $100 \mathrm{~mm}$ potassium phosphate buffer (pH 7.4), $20 \mu \mathrm{l}$ of distilled water or citrus extract solution at final concentrations of 0.01 to $5 \mathrm{mg} / \mathrm{ml}$, an NADPH generating system $\left[1.3 \mathrm{~mm} \beta-\mathrm{NADP}^{+}, 3.3 \mathrm{~mm}\right.$ glucose-6-phosphate, $0.4 \mathrm{IU} / \mathrm{ml}$ glucose-6-phosphate dehydrogenase, and $3.3 \mathrm{~mm} \mathrm{MgCl}_{2}, 0.5 \mathrm{mg} / \mathrm{ml}$ human microsomes, and $10 \mu \mathrm{m}$ midazolam (CYP3A4) or dextromethorphan (CYP2D6). The concentrations of each substrate used were around the expected $K_{\mathrm{m}}$ values: $25 \mu \mathrm{m}$ midazolam, $50 \mu \mathrm{m}$ dextromethorphan. ${ }^{12}$ The reaction was initiated by addition of the NADPH generating system after preincubation for $5 \mathrm{~min}$ at $37^{\circ} \mathrm{C}$, and was carried out for $10 \mathrm{~min}$ at $37^{\circ} \mathrm{C}$ with constant shaking.

For the assay of MD1H activities, the reaction was terminated by the addition of $0.5 \mathrm{ml}$ of $0.1 \mathrm{M} \mathrm{Na}_{2} \mathrm{CO}_{3}$ and $0.1 \mathrm{ml}$ of $3.0 \mu \mathrm{g} / \mathrm{ml}$ diazepam methanol solution as an internal standard. Then $5 \mathrm{ml}$ ethyl acetate was added and the mixture shaken for $15 \mathrm{~min}$. After centrifugation at $5000 \times \boldsymbol{g}$ for $15 \mathrm{~min}$, the organic layer was evaporated with a centrifugal evaporator (Tokyo Rikakikai Co., Ltd., Tokyo, Japan). The residues were dissolved with $100 \mu \mathrm{l}$ of $20 \%$ of acetonitrile in $10 \mathrm{~mm}$ phosphate buffer ( $\mathrm{pH} 7.4$ ), and analyzed using highperformance liquid chromatography (HPLC) as described below. The HPLC system consisted of a model LC10A HPLC (Shimadzu, Kyoto, Japan). Chromatography was conducted in a $3.5 \mu \mathrm{m}$ Symmetry C18 column $(4.6 \times 150 \mathrm{~mm}$, $5 \mu \mathrm{m}$ ) (Waters, Milford, MA, U.S.A.). The column temperature was set at $40^{\circ} \mathrm{C}$, and a UV-detector was set at $254 \mathrm{~nm}$. The mobile phase consisted of acetonitrile : methanol: $10 \mathrm{~mm}$ potassium phosphate buffer (pH 7.4) $(7: 5: 12)$. Flow rate was maintained at $1 \mathrm{ml} / \mathrm{min}$.

For the assay of DMOD activities, the reaction was terminated by the addition of $200 \mu \mathrm{l}$ of acetonitrile. Each sample was then filtered through $0.45 \mu \mathrm{m}$ filter after centrifugation at
$5000 \times \boldsymbol{g}$ for $10 \mathrm{~min}$. The filtrates were analyzed using HPLC. The HPLC system consisted of a model LC10A HPLC equipped with a fluorescence detector (RF-10AXL, Shimadzu, Kyoto, Japan). Chromatography was conducted using a Inertsil ODS- 2 column $(4.6 \times 250 \mathrm{~mm}, 5 \mu \mathrm{m})(\mathrm{GL}$ Sciences, Tokyo, Japan). The column temperature was set at $40^{\circ} \mathrm{C}$, and the detector was set at 285 (excitation) and $310 \mathrm{~nm}$ (emission). The mobile phase consisted of acetonitrile: $10 \mathrm{~mm}$ citric acid buffer ( $\mathrm{pH} 7.4)(35: 65)$. Flow rate was maintained at $1 \mathrm{ml} / \mathrm{min}$.

CYP2C9 activity was determined using a P450-Glo ${ }^{\mathrm{TM}}$ CYP2C9 assay (Promega, Madison, WI, U.S.A.) according to the manufacturer's instructions (since the HPLC peak derived from citrus extracts interfered with the determination of the metabolite of the substrate on the chromatogram). In brief, the above mentioned incubation mixture was used and the reaction were performed in a 96-well plate [OptiPlate ${ }^{\mathrm{TM}}$ 96 (PerkinElmer, Waltham, MA, U.S.A.)] for $30 \mathrm{~min}$. We used $100 \mu \mathrm{M}$ of $6^{\prime}$-deoxyluciferin (luciferin-H) as a substrate for $\mathrm{CYP} 2 \mathrm{C} 9$ and $20 \mu \mathrm{g}$ human liver microsomes. CYP2C9 converts 6'-deoxyluciferin (luciferin-H) to luciferin (LUC) and the production of luciferin by CYP2C9 was determined using luciferase assays. Luminescence was measured using FLUOstar Optima (Moritex, Tokyo, Japan).

Duplicate determinations of CYP isoforms were performed.

Measurement of Flavonoids and Furanocoumarins in Citrus Extracts For measurement of flavonoids, 100 $300 \mathrm{mg}$ of each citrus extract was refluxed 3 times with $50 \mathrm{ml}$ methanol for $30 \mathrm{~min}$ at $80^{\circ} \mathrm{C}$. The samples were concentrated under vacuum and dissolved in $200 \mathrm{ml}$ methanol. Each sample was filtered through a $0.45 \mu \mathrm{m}$ membrane filter (GL Science), and 5-10 $\mu \mathrm{l}$ was injected into the HPLC. Chromatography was conducted using a TSK gel ODS-120T column $(4.6 \times 250 \mathrm{~mm}, 4 \mu \mathrm{m})$ (TOSOH, Tokyo, Japan). The column temperature was set at $40^{\circ} \mathrm{C}$, and a UV-detector was set at $280 \mathrm{~nm}$. The mobile phase consisted of $0.1 \%$ $\mathrm{H}_{3} \mathrm{PO}_{4}: \mathrm{CH}_{3} \mathrm{CN}(9: 1)(\mathrm{A})$ and $0.1 \% \mathrm{H}_{3} \mathrm{PO}_{4}: \mathrm{CH}_{3} \mathrm{CN}(2: 8)$ (B). The mobile phase program consisted of three periods; $100 \% \mathrm{~A}$ ( 0 to $25 \mathrm{~min}$ ), $70 \% \mathrm{~A}$ ( 25 to $35 \mathrm{~min}$ ) and $100 \% \mathrm{~B}$ ( 35 to $45 \mathrm{~min}$ ). Flow rate was maintained at $0.8 \mathrm{ml} / \mathrm{min}$.

For measurement of bergapten, $300 \mu \mathrm{l}$ of each $1 \mathrm{mg} / \mathrm{ml}$ citrus extract was mixed with $4 \mathrm{ml}$ ethylacetate and $100 \mu \mathrm{l}$ of 
$3 \mu \mathrm{M}$ testosterone, as an internal standard. After stirring for $2 \mathrm{~min}$, samples were centrifuged at $500 \times \boldsymbol{g}$ for $15 \mathrm{~min}$. The supernatant was evaporated to dryness and stored at $-20^{\circ} \mathrm{C}$ until HPLC analysis. Residues were dissolved in $200 \mu \mathrm{l}$ of $55 \%(\mathrm{v} / \mathrm{v})$ methanol for HPLC. Chromatography was conducted using an Inertsil ODS-3 column $(4.6 \times 250 \mathrm{~mm}, 5 \mu \mathrm{m})$ (GL Sciences). The column temperature was set at $40^{\circ} \mathrm{C}$, and UV-detection at $254 \mathrm{~nm}$. The mobile phase consisted of $55 \%$ methanol. Flow rate was maintained at $1.2 \mathrm{ml} / \mathrm{min}$.

For measurement of $6^{\prime}, 7^{\prime}-\mathrm{DHB}, 300 \mu \mathrm{l}$ of each $1 \mathrm{mg} / \mathrm{ml}$ citrus extract was mixed with $4 \mathrm{ml}$ ethylacetate and $100 \mu \mathrm{l}$ $50 \mathrm{~mm}$ anthracene, as an internal standard. After stirring for $2 \mathrm{~min}$, samples were centrifuged at $500 \times \boldsymbol{g}$ for $15 \mathrm{~min}$. The supernatant was evaporated to dryness and stored at $-20^{\circ} \mathrm{C}$ until HPLC analysis. Residues were dissolved in $100 \mu \mathrm{l}$ of acetonitrile for HPLC.

For measurement of bergamottin, $300 \mu 1$ of each $10 \mathrm{mg} / \mathrm{ml}$ citrus extract was mixed with $4 \mathrm{ml}$ ethylacetate and $100 \mu \mathrm{l}$ of $50 \mathrm{~mm}$ anthracene, as an internal standard. After stirring for $2 \mathrm{~min}$, samples were centrifuged at $500 \times \boldsymbol{g}$ for $15 \mathrm{~min}$. The supernatants were evaporated to dryness and stored at $-20{ }^{\circ} \mathrm{C}$ until HPLC analysis. Residues were dissolved in $100 \mu 1$ acetonitrile for HPLC.

For both $6^{\prime}, 7^{\prime}$-DHB and bergamottin chromatography was conducted using an Inertsil ODS-3 column $(4.6 \times 150 \mathrm{~mm}$, $5 \mu \mathrm{m})$ (GL Sciences). The column temperature was set at $40^{\circ} \mathrm{C}$, and the UV-detector was set at $310 \mathrm{~nm}$. The mobile phase consisted of $75 \%$ methanol. Flow rate was maintained at $1.0 \mathrm{ml} / \mathrm{min}$.

The amount of each component was determined from a standard curve prepared using the same procedures. For naringin and neohesperidin, the calibration curve was linear, in the range of 3.125 to $200 \mu \mathrm{g} / \mathrm{ml}$. For hesperidin and narirutin, the calibration curve was linear, in the range 6.25 to $200 \mu \mathrm{g} / \mathrm{ml}$.

Data Analysis All data are analyzed using the average of the duplicate determinations, and the $50 \%$ inhibitory concentration $\left(\mathrm{IC}_{50}\right)$ values were calculated by fitting the following Hill equation to CYP inhibition data using a nonlinear regression (WinNonlin, Pharsight Co., Mountain View, CA, U.S.A.):

$$
A=100 \times\left(1-\frac{C^{\gamma}}{C^{\gamma}+\mathrm{IC}_{50}}\right)
$$

where $A$ is the observed remaining CYP activity for control, $C$ is the concentration of citrus extracts, $\mathrm{IC}_{50}$ is the concentration of citrus extracts at which 50\% inhibition of CYP activity is observed, and $\gamma$ is the Hill coefficient.

The correlations among $\mathrm{IC}_{50}$ values of citrus extracts for 3 CYP were evaluated using the Spearman correlations (Statview, SAS Institute, Cary, NC, U.S.A.).

\section{RESULTS}

Figure 1 shows the inhibitory effects of extracts from im-

- CYP3A4

- CYP2D6

$\rightarrow$ CYP2C9

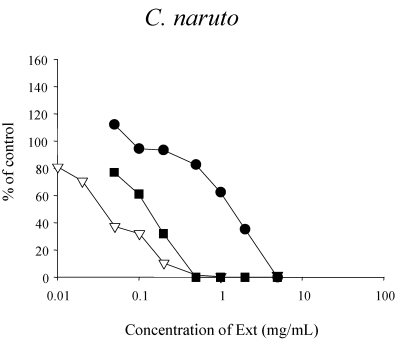

C. aurantiun var. daidai

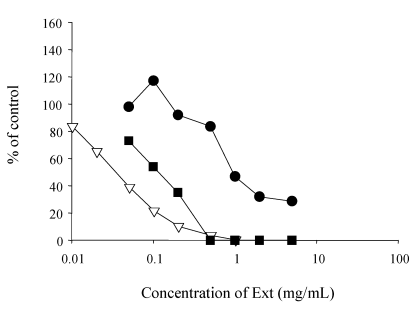

C. sinensis var. grasiliensis
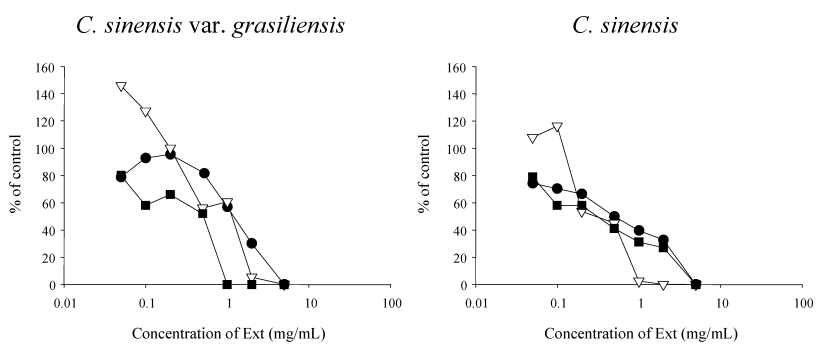

C. grandis

C. limon
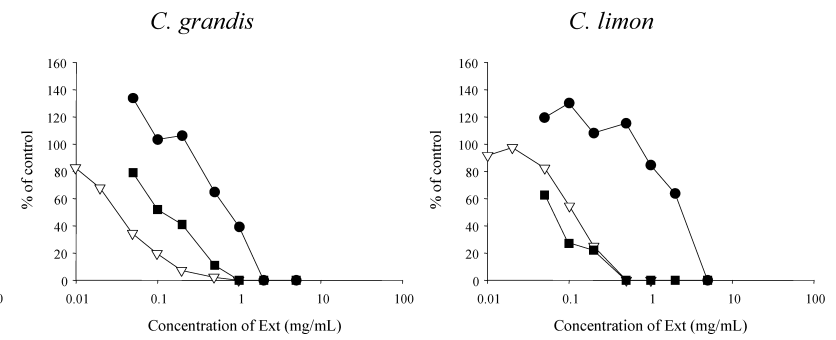

Fig. 1. Inhibitory Effects of Citrus Extracts on CYP3A4, CYP2D6 and CYP2C9 Activities

Concentration of each citrus extract; $0.01-10 \mathrm{mg} / \mathrm{ml}$. Amounts of metabolite produced by each CYP isoform were measured using HPLC. 
mature citrus fruits on the activities of MD1H (CYP3A4), DMOD (CYP2D6) and LUC (CYP2C9). Inhibitory effects were evaluated by measuring the suppression of metabolite formation from the specific substrate for each CYP isoform. All examined citrus extracts inhibited the activities of CYP isoforms in a concentration-dependent manner. $\mathrm{The}^{\mathrm{IC}_{50}}$ values calculated using Eq. 1 are shown in Table 1 in decreasing order of CYP3A4 $\mathrm{IC}_{50}$ as well as the yield (\%) of extract for each citrus fruit. The yield (\%) of all citrus extracts examined ranged from 14 to $25 \%$. Some citrus extracts showed

Table 2. The Values of $\mathrm{IC}_{50}$ for Each CYP Isoform of Citrus Fruits in Decreasing Order of CYP3A4 $\mathrm{IC}_{50}$

\begin{tabular}{lccc}
\hline \hline & \multicolumn{3}{c}{$\mathrm{IC}_{50}$ (mg dried fruits/ml) } \\
\cline { 2 - 4 } & CYP3A4 & CYP2D6 & CYP2C9 \\
\hline C. unshiu & $3.56 \pm 0.89$ & $13.1 \pm 3.32$ & $4.13 \pm 0.49$ \\
C. sulcata & $2.74 \pm 0.96$ & $9.54 \pm 1.42$ & $3.50 \pm 0.46$ \\
C. iyo & $2.59 \pm 0.52$ & $2.18 \pm 0.40$ & $4.48 \pm 0.46$ \\
C. sinensis & $1.91 \pm 0.64$ & $3.48 \pm 1.35$ & $2.06 \pm 0.64$ \\
C. sinensis var. grasiliensis & $1.69 \pm 0.79$ & $7.42 \pm 1.01$ & $3.20 \pm 1.24$ \\
C. reticulata & $1.10 \pm 0.45$ & $7.70 \pm 2.30$ & $0.65 \pm 0.05$ \\
C. naruto & $0.86 \pm 0.07$ & $9.07 \pm 1.21$ & $0.29 \pm 0.07$ \\
C. grandis & $0.83 \pm 0.07$ & $4.31 \pm 0.83$ & $0.21 \pm 0.07$ \\
C. aurantiun var. daidai & $0.56 \pm 0.05$ & $5.71 \pm 1.63$ & $0.15 \pm 0.05$ \\
C. natsudaidai & $0.46 \pm 0.13$ & $6.33 \pm 1.27$ & $0.21 \pm 0.04$ \\
C. paradisi & $0.42 \pm 0.07$ & $2.78 \pm 0.69$ & $0.42 \pm 0.07$ \\
C. limon & $0.35 \pm 0.05$ & $9.65 \pm 1.65$ & $0.55 \pm 0.05$ \\
\hline
\end{tabular}

particularly high inhibitory effects on MD1H and LUC activities; of these, C. paradisi (grapefruit) showed the highest inhibitory effects on MD1H activities as determined by the $\mathrm{IC}_{50}$ value. C. iyo exhibited the greatest inhibitory effect on DMOD, and $C$. grandis and C. aurantiun var. daidai on LUC. The lowest inhibitory effects on CYP activities among the extracts tested were observed for $C$. unshiu. The $\mathrm{IC}_{50}$ value of $C$. unshiu for CYP3A4 was about 15 times higher compared to that of $C$. paradisi. To understand the actual inhibitory effect as fruit, the $\mathrm{IC}_{50}$ values were converted to equivalent $\mathrm{mg}$ dried fruit by using the yields shown in Table 1. Table 2 shows the $\mathrm{IC}_{50}(\mathrm{mg}$ dried fruits $/ \mathrm{ml}$ ) estimated from yield (\%) shown in Table 1. Based on $\mathrm{IC}_{50}$ values (mg dried fruits $/ \mathrm{ml}$ ), C. limon showed the highest inhibitory effects on MD1H activities. C. iyo exhibited the greatest inhibitory effect on DMOD, and C. aurantiun var. daidai on LUC.

To clarify the relationships among the inhibitory effects of each citrus extract on CYP, we carried out correlation analysis among the $\mathrm{IC}_{50}$ values for the three CYP isoforms. The results are shown in Fig. 2. Interestingly, the inhibition of MD1H (CYP3A4) activity was strongly correlated with inhibition of LUC (CYP2C9) activity ( $r=0.9444)$, although the latter was determined by bioluminescemce assay. No correlations were found among inhibitory effects on other CYP isoforms.

To elucidate the differences in $\mathrm{IC}_{50}$ values among the extracts, we determined the amounts of certain flavonoids and
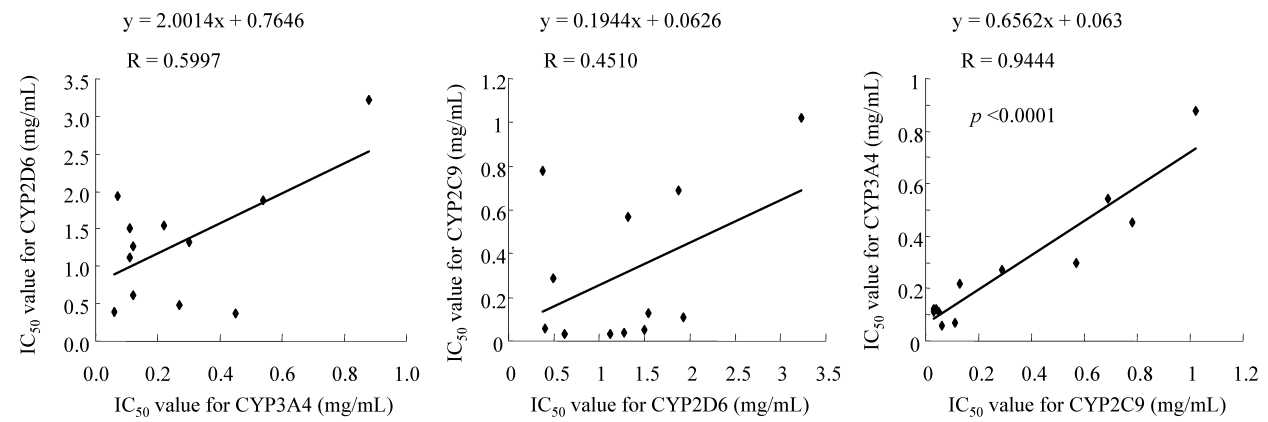

Fig. 2. Correlations among Inhibitory Effects on Activities of the Three CYP Isoforms

There was a significant correlation between CYP2C9 and CYP3A4 $(p<0.0001)$.

Table 3. The Contents of Flavonoid and Furanocoumarin in Citrus Extracts in the Order Corresponding to IC $_{50}$ Values for CYP3A4

\begin{tabular}{|c|c|c|c|c|c|c|c|c|}
\hline & \multirow{3}{*}{$\begin{array}{l}\mathrm{IC}_{50} \text { for } \\
\text { CYP3A4 } \\
(\mathrm{mg} / \mathrm{ml})\end{array}$} & \multicolumn{7}{|c|}{ Content (mg/g extract) } \\
\hline & & \multicolumn{4}{|c|}{ Flavonoid } & \multicolumn{3}{|c|}{ Furanocoumarin } \\
\hline & & Naringin & Hesperidin & Narirutin & Neohesperidin & Bergapten & $6^{\prime}, 7^{\prime}-\mathrm{DHB}$ & Bergamottin \\
\hline C. paradisi & $0.06 \pm 0.01$ & 27.4 & - & 265.2 & - & 0.044 & 1.569 & 0.0314 \\
\hline C. limon & $0.07 \pm 0.01$ & - & 35.2 & - & 3.7 & 1.100 & - & 0.6654 \\
\hline C. aurantium var. daidai & $0.11 \pm 0.01$ & - & - & 178.7 & 94.7 & 1.400 & 0.206 & - \\
\hline C. natsudaidai & $0.11 \pm 0.03$ & 8.0 & - & 206.4 & 37.0 & 0.008 & - & 0.0017 \\
\hline C. naruto & $0.12 \pm 0.01$ & 21.9 & - & 250.3 & 30.5 & - & 0.460 & 0.0091 \\
\hline C. grandis & $0.12 \pm 0.01$ & - & - & 276.2 & - & - & 0.347 & 0.0024 \\
\hline C. reticulata & $0.22 \pm 0.09$ & 28.0 & 131.0 & - & 13.5 & 0.050 & - & — \\
\hline C. sinensis & $0.27 \pm 0.09$ & 38.7 & 60.5 & - & - & 0.021 & 0.106 & - \\
\hline C. sinensis var. grasiliensis & $0.30 \pm 0.14$ & 51.2 & 50.3 & - & - & 0.013 & - & - \\
\hline C. iyo & $0.45 \pm 0.09$ & 95.2 & 83.2 & - & - & - & - & - \\
\hline C. sulcata & $0.54 \pm 0.19$ & 150.3 & 72.1 & - & - & 0.013 & - & - \\
\hline C. unshiu & $0.88 \pm 0.22$ & 23.0 & 40.5 & - & - & 0.058 & - & - \\
\hline
\end{tabular}

The amounts of narirutin, hesperidin, naringin and neohesperidin as flavonoid and bergapten, $6^{\prime}, 7^{\prime}$-dihydroxybergamottin $\left(6^{\prime}, 7^{\prime}\right.$-DHB) and bergamottin as furanocoumarin were measured. - in the table indicated not detected. 
furanocoumarins in the extracts. The results are shown in their order of $\mathrm{IC}_{50}$ values for CYP3A4 (Table 3). With respect to flavonoids, the extracts containing narirutin usually also contained hesperidin. The distribution of naringin and neohesperidin was generally similar among the extracts. Compared to flavonoids, lower amounts of furanocoumarins were observed in each citrus extract, although almost all extracts contained bergapten. The extracts containing naringin usually also contained bergamottin and $6^{\prime}, 7^{\prime}$-DHB. Citrus extracts containing relatively large amounts of naringin, $6^{\prime}, 7^{\prime}$-DHB and bergamottin exhibited higher inhibitory effects on MD1H activity. In contrast, citrus extracts containing narirutin and hesperidin without naringin have generally weak inhibitory effects on CYP3A4 activity.

\section{DISCUSSION}

Our study had two major findings. First, information on the inhibitory effects of extracts from immature fruits of 12 citrus cultivars on CYP activity was obtained. Second, extracts containing larger amounts of naringin, $6^{\prime}, 7^{\prime}$-DHB and bergamottin showed relatively strong inhibitory effects on CYP activities.

C. paradisi shows the most marked inhibition for CYP3A4, CYP2D6 and CYP2C9 within the 12 citrus extracts examined. The extracts, including $C$. paradisi, with lower $\mathrm{IC}_{50}$ values for CYP3A4 contained high proportions of naringin, $6^{\prime}, 7^{\prime}$-DHB and bergamottin compared to the other citrus extracts, suggesting that these components could be an important factor in the inhibition of CYP3A4 activities. Inhibitory effects on CYP3A4 activities increased as the amounts of naringin and bergamottin increased. Nevertheless, inhibition by flavonoids is equivocal; naringin, for example, has been shown to cause marked inhibition ${ }^{3)}$ or no inhibition $^{4)}$ of nifedipine metabolism. In vivo, it has been reported that naringin affected the pharmacokinetics of some drugs metabolized by CYP3A4. ${ }^{13,14)}$ Other flavonoids in grapefruit juice inhibited activities of CYP1A2 and CYP2A6 in addition to CYP3A4. ${ }^{15)}$ Moreover, it has been reported that naringin and naringenin, the aglycone of naringin, are not the main components in grapefruit juice responsible for CYP3A4 inhibition ${ }^{16-18)}$ Naringin also inhibits the activity of transporters such as P-glycoprotein ${ }^{19)}$ or organic aniontransporting polypeptide 1A2 (OATP1A2). ${ }^{20)}$ Further studies are needed to clarify the effects of citrus extracts on transporter function. On the other hand, it has been reported that furanocoumarins function as major CYP3A4 inhibitors. The activities of CYP isoforms 1A2, 2A6, 2C9, 2C19, 2D6 and $2 \mathrm{E} 1$ in human liver microsomes were found to be inhibited by furanocoumarins. ${ }^{21)}$ The involvement of furanocoumarin in CYP inhibition was directly indicated by using a furanocoumarin-free grapefruit juice. ${ }^{22)}$ Alternatively, it has been reported that some furanocoumarins induced CYP activity in experimental animals and humans. ${ }^{23-27)}$ Other components in these citrus extracts, such as furanocoumarin dimers, may be involved in their inhibitory effects. It has been reported that furanocoumarin dimers, possibly derived from the geranyloxy monomer $\left(6^{\prime}, 7^{\prime}\right.$-DHB), function as potent and selective inhibitors of CYP3A4. , $^{8,28,29)}$

Inhibitory effects for the relative yield of each fruit is also interesting to clarify the practical influence of citrus fruits on
CYP activity, although the immature fruits were used in this study. In Table 2, evaluated $\mathrm{IC}_{50}(\mathrm{mg}$ fruits $/ \mathrm{ml})$ for $\mathrm{CYP}$ showed the relatively strong inhibitory effects of $C$. paradisi. C. unshiu and C. sulcata exhibited relatively weak inhibition of CYP activities as well as the higher $\mathrm{IC}_{50}$ value for extract weight, suggesting that the frequencies of drug interaction mediated by CYP inhibition could be low compared to other citrus fruits. $\mathrm{IC}_{50}(\mathrm{mg}$ fruits $/ \mathrm{ml})$ exhibited a similar trend to $\mathrm{IC}_{50}(\mathrm{mg} / \mathrm{ml})$ for each citrus extract.

Interestingly, our data showed that there was a positive correlation between the inhibition of CYP2C9 activity and inhibition of CYP3A4 by citrus extracts, although the inhibitory assays for CYP3A4 and CYP2C9 were performed by the different methods, that is, HPLC and bioluminescence methods. We cannot explain the exact mechanisms underlying the inhibition to both CYP3A4 and CYP2C9 as our experiments showed only the degree of inhibition by each citrus extract. The positive correlation between inhibition of CYP2C9 and that of CYP3A4 by citrus extracts could reflect a similar inhibitory mechanism. It is also possible that an interaction between substrates for CYP2C9 and CYP3A4 and citrus extracts occurs. In the case of irreversible inhibition; mechanism-based inhibition, the inactivator first binds to and is then catalytically activated by a target enzyme to a reactive intermediate that covalently binds to heme and/or protein in the enzyme active site, resulting in an irreversible loss of enzymatic activity. However, a similar competitive mechanism could be involved in the inhibition of CYP2C9 and CYP3A4 because this study, the correlation was derived from a simple reversible inhibition study. The correlation in inhibition between CYP3A4 and CYP2C9 and the precise mechanisms underlying this correlation need to be examined in detail using other specific substrates for each isoform and/or recombinant CYP isoforms.

Experiments on CYP activities via mechanism-based inhibition such as furafylline, ${ }^{12)} 8$-methoxypsoralen ${ }^{30,31)}$ and naturally occurring coumarins ${ }^{32)}$ indicate that loss of catalytic activities may be caused by denaturation of the apoprotein, modification of the heme group, or covalent binding of the inactivator to the active site of the enzyme. Tassaneeyakul et $a l$. have reported that CYP-inhibition by furanocoumarins in grapefruit juice depends upon the preincubation period. ${ }^{9)}$ The same authors have suggested that inhibition by flavonoids and furanocoumarins was irreversible and resulted from a catalytic process. We did not investigate the mechanisms of inhibition of furanocoumarin components of grapefruit juice on CYP isoforms in the present study. However, furanocoumarins have previously been reported as mechanismbased inhibitors of CYP1A $1^{32)}$ and CYP2A6. ${ }^{31,33)}$ It is unclear whether flavonoids and furanocoumarins are involved in CYP2C9 inhibition via mechanism-based processes. Silybin, a major flavonoid constituent of milk thistle extract, is a mechanism-based inactivator of both CYP3A4 and CYP2C9 and this interaction can lead to irreversible enzyme degradation. $^{32)}$ Further studies are needed to clarify the precise mechanisms of CYP inhibition, including mechanism-based processes.

In this study, we used immature fruits harvested in August. The amounts of flavonoids and furanocoumarins in citrus extracts vary according to the genetic background, the processing method and maturity. ${ }^{5,34-36)}$ For example, the amounts of 
flavonoids in citrus extracts derived from immature fruits are higher compared to those from mature fruits. Thus, the antiallergic effect of hesperidin weakens with the maturity of the fruit. Recently, citrus fruit-drug interactions have been widely reported. Furanocoumarins such as bergapten and bergamottin in grapefruit juice are potent inhibitors of CYP3A4 activity. ${ }^{2-4)}$ Thus, the drug interaction induced by an extract from immature $C$. unshiu fruit might be expected to be less than that of other citrus extracts probably due to the lower levels of furanocoumarin in C. unshiu. This was reflected by the greater $\mathrm{IC}_{50}$ value for CYP activities. In addition, the antiallergic effect of $C$. unshiu is higher compared to those of other citrus extracts. ${ }^{37,38)}$ The results of this study suggest that $C$. unshiu has an antiallergic effect, but shows the relatively low frequency of drug interaction. $C$. paradisi (grapefruit) showed strong CYP inhibition, consistent with previous reports on $C$. paradisi and grapefruit juice. ${ }^{39-45)}$ Grapefruit juice enhances the bioavailability or systemic exposure of numerous CYP3A4 substrates by inhibiting intestinal first-pass metabolism. For the other citrus extracts examined, further studies should investigate the inhibitory effects on substrate metabolism, as shown by the CYP inhibition patterns of each citrus extract.

In conclusion, our present results showed that all citrus extracts examined inhibited CYP activities in a dose-dependent manner. Citrus extracts having lower $\mathrm{IC}_{50}$ values such as $C$. paradisi contained naringin and furanocoumarins in abundance. These findings may help elucidate the roles of flavonoids and furanocoumarins in CYP inhibition, and suggest that citrus extracts containing high levels of narirutin and hesperidin and lower levels of furanocoumarins such as C. unshiu are favorable as antiallergic functional ingredients.

Acknowledgments The authors would like to thank Ms. Keiko Ubagai for her assistance with experiments. This study was partially supported by a grant from the "High-Tech Research Center" Project for Private Universities: matching fund subsidy from MEXT (Ministry of Education, Culture, Sports, Science and Technology), 2007.

\section{REFERENCES}

1) Middleton E., Jr., Kandaswami C., Theoharides T. C., Pharmacol. Rev., 52, 673-751 (2000).

2) Bailey D. G., Malcolm J., Arnold O., Spence J. D., Br. J. Clin. Pharmacol., 46, 101-110 (1998).

3) Guengerich F. P., Kim D. H., Carcinogenesis., 11, 2275-2279 (1990).

4) Miniscalco A., Lundahl J., Regardh C. G., Edgar B., Eriksson U. G., J. Pharmacol. Exp. Ther, 261, 1195-1199 (1992).

5) Paine M. F., Hart H. L., Ludington S. S., Haining R. L., Rettie A. E., Zeldin D. C., Drug Metab. Dispos., 34, 880-886 (2006).

6) Kubo M., Fujita T., Nishimura S., Tokunaga M., Matsuda H., Gato T., Tomohiro N., Sasaki K., Utsunomiya N., Nat. Med., 58, 284-294 (2004).

7) Edwards D. J., Bellevue F. H., 3rd, Woster P. M., Drug Metab. Dispos., 24, 1287-1290 (1996).

8) Guo L. Q., Fukuda K., Ohta T., Yamazoe Y., Drug Metab. Dispos., 28, $766-771(2000)$

9) Tassaneeyakul W., Guo L. Q., Fukuda K., Ohta T., Yamazoe Y., Arch. Biochem. Biophys., 378, 356-363 (2000).

10) Lown K. S., Bailey D. G., Fontana R. J., Janardan S. K., Adair C. H., Fortlage L. A., Brown M. B., Guo W., Watkins P. B., J. Clin. Invest.,
99, 2545-2553 (1997)

11) Mays D. C., Hilliard J. B., Wong D. D., Chambers M. A., Park S. S., Gelboin H. V., Gerber N., J. Pharmacol. Exp. Ther, 254, 720-731 (1990).

12) Liu K. H., Kim M. J., Jeon B. H., Shon J. H., Cha I. J., Cho K. H., Lee S. S., Shin J. G., J. Clin. Pharm. Ther, 31, 83-91 (2006).

13) Mays D. C., Nawoot S., Hilliard J. B., Pacula C. M., Gerber N., J. Pharmacol. Exp. Ther, 243, 227-233 (1987).

14) Lim S. C., Choi J. S., Biopharm. Drug Dispos., 27, $443-447$ (2006).

15) Alvarez-Gonzalez I., Madrigal-Bujaidar E., Dorado V., EspinosaAguirre J. J., Mutat. Res., 480-481, 171-178 (2001).

16) Fuhr U., Klittich K., Staib A. H., Br. J. Clin. Pharmacol., 35, 431436 (1993).

17) Bailey D. G., Arnold J. M., Munoz C., Spence J. D., Clin. Pharmacol. Ther, 53, 637-642 (1993).

18) Bailey D. G., Arnold J. M., Strong H. A., Munoz C., Spence J. D., Clin. Pharmacol. Ther, 54, 589-594 (1993).

19) Fuhr U., Drug Saf., 18, 251-272 (1998).

20) Spahn-Langguth H., Langguth P., Eur. J. Pharm. Sci., 12, 361-367 (2001).

21) Sridar C., Goosen T. C., Kent U. M., Williams J. A., Hollenberg P. F., Drug Metab. Dispos., 32, 587-594 (2004).

22) He K., Iyer K. R., Hayes R. N., Sinz M. W., Woolf T. F., Hollenberg P. F., Chem. Res. Toxicol., 11, 252-259 (1998).

23) Paine M. F., Widmer W. W., Hart H. L., Pusek S. N., Beavers K. L., Criss A. B., Brown S. S., Thomas B. F., Watkins P. B., Am. J. Clin. Nutr., 83, 1097-1105 (2006).

24) Apseloff G., Hilliard J. B., Gerber N., Mays D. C., Xenobiotica, 21, 1461-1471 (1991).

25) Apseloff G., Shepard D. R., Chambers M. A., Nawoot S., Mays D. C., Gerber N., Drug Metab. Dispos., 18, 298-303 (1990).

26) Bendriss E. K., Bechtel Y., Bendriss A., Humbert P. H., Paintaud G., Magnette J., Agache P., Bechtel P. R., Br. J. Clin. Pharmacol., 41, 421-424 (1996).

27) Maenpaa J., Juvonen R., Raunio H., Rautio A., Pelkonen O., Biochem. Pharmacol., 48, 1363-1369 (1994).

28) Bailey D. G., Dresser G. K., Leake B. F., Kim R. B., Clin. Pharmacol. Ther, 81, 495-502 (2007).

29) Row E., Brown S. A., Stachulski A. V., Lennard M. S., Drug Metab. Dispos., 34, 324-330 (2006).

30) Kunze K. L., Trager W. F., Chem. Res. Toxicol., 6, 649-656 (1993).

31) Koenigs L. L., Peter R. M., Thompson S. J., Rettie A. E., Trager W. F., Drug Metab. Dispos., 25, 1407-1415 (1997).

32) Draper A. J., Madan A., Parkinson A., Arch. Biochem. Biophys., 341, 47-61 (1997)

33) Cai Y., Baer-Dubowska W., Ashwood-Smith M. J., Ceska O., Tachibana S., DiGiovanni J., Chem. Res. Toxicol., 9, 729-736 (1996).

34) Fukuda K., Ohta T., Oshima Y., Ohashi N., Yoshikawa M., Yamazoe Y., Pharmacogenetics, 7, 391-396 (1997).

35) Ranganna S., Govindarajan V. S., Ramana K. V., Crit. Rev. Food Sci. Nutr., 19, 1-98 (1983).

36) Ranganna S., Govindarajan V. S., Ramana K. V., Crit. Rev. Food Sci. Nutr., 18, 313-386 (1983).

37) Bailey D. G., Arnold J. M., Spence J. D., Clin. Pharmacokinet., 26, 91-98 (1994).

38) Kubo M., Yano M., Matsuda H., Yakugaku Zasshi, 109, 835-842 (1989).

39) Matsuda H., Yano M., Kubo M., Iinuma M., Oyama M., Mizuno M., Yakugaku Zasshi, 111, 193-198 (1991).

40) Bailey D. G., Spence J. D., Munoz C., Arnold J. M., Lancet, 337, 268-269 (1991).

41) Bailey D. G., Arnold J. M., Bend J. R., Tran L. T., Spence J. D., Br. J. Clin. Pharmacol., 40, 135-140 (1995).

42) Benton R. E., Honig P. K., Zamani K., Cantilena L. R., Woosley R. L., Clin. Pharmacol. Ther, 59, 383-388 (1996).

43) Ducharme M. P., Provenzano R., Dehoorne-Smith M., Edwards D. J., Br. J. Clin. Pharmacol., 36, 457-459 (1993).

44) Ducharme M. P., Warbasse L. H., Edwards D. J., Clin. Pharmacol. Ther., 57, 485-491 (1995).

45) Kupferschmidt H. H., Ha H. R., Ziegler W. H., Meier P. J., Krahenbuhl S., Clin. Pharmacol. Ther, 58, 20-28 (1995). 